\title{
An unusual presentation of inflammatory myopathy in a patient on natalizumab treatment for multiple sclerosis: A case report and review of myopathological classification of inflammatory myopathy
}

\begin{abstract}
Acquired immune and inflammatory myopathies (IIMs) are traditionally subdivided into dermatomyositis, polymyositis, inclusion body myositis (IBM) and necrotizing autoimmune myopathy (NAM). Our patient is a 38-year old female who had history of Multiple Sclerosis and was on Natalizumab. Almost a year later, she presented with acute proximal bilateral upper extremity weakness with elevated CPK. She was initially labeled as having 'viral myositis'. Her subsequent two admissions demonstrated worsening of muscle weakness with dysphagia which was initially unresponsive to high dose of steroids. She had an EMG which showed irritative myopathy and a muscle biopsy which showed IMPP. She eventually responded to pulse dose of steroids and IVIG and Natalizumab was held. The temporal relationship between the development of inflammatory myopathy in our patient and subsequent improvement in her course after discontinuation of the drug suggests that natalizumab may have played a role in our patient's disease and warrants further investigation and vigilance. In addition to the case report, we hope to elaborate on the myopathological descriptions increasingly being used to describe the IIMs and to explore the potential link between natalizumab and the onset of IIM in our patient.
\end{abstract}

Keywords: natalizumab myositis • multiple sclerosis $•$ acquired immune and inflammatory myopathies

\section{Introduction}

Acquired immune and inflammatory myopathies (IIMs) are traditionally subdivided into dermatomyositis, polymyositis, inclusion body myositis (IBM) and necrotizing autoimmune myopathy (NAM) [1,2]. The presence of myositis specific antibodies and myopathological descriptions help to further delineate these disorders and may help prognostically. We describe an unusual presentation of acute onset inflammatory myopathy in a patient who was on natalizumab treatment for multiple sclerosis (MS) and who was initially resistant to high dose steroids. She was followed by both the rheumatology and neuromuscular services who characterized her as having an immune myopathy with perimysial pathology (IMPP). In addition to the case report, we hope to elaborate on the myopathological descriptions increasingly being used to describe the IIMs and to explore the potential link between natalizumab and the onset of IIM in our patient.

\section{Case}

We present a case of a 38-year-old female with a medical history significant for Grave's disease postradioablation, hypertension, and anemia. She also had a history of Multiple Sclerosis diagnosed in 2014 when she first presented with impaired gait and dysarthria after a sinus infection. Her MRI brain findings at that time showed several small enhancing lesions in the white matter: left cerebellar peduncle, left lateral ventricle, left periventricular white matter, left pons, right and left medial longitudinal fasciculus, and left pons. Her course was characterized as relapsing. She was previously treated with high doses of steroids and intravenous cyclophosphamide with improvement. However, in December 2015, she relapsed and was begun on natalizumab (Tysabri). In September 2016, she began to have a headache and neck pain. Work-up including MRI of the brain revealed a CSF leak of unknown etiology and she received a blood patch. During that time, she also started complaining of

\author{
Beenish Zulfiqar ${ }^{* 1}$, Jacquelin
Chua $^{2}$, Stacy Weinberg ${ }^{2}$ \& \\ Beenish Zulfiqar ${ }^{* 1}$, Jacquelin
Chua $^{2}$, Stacy Weinberg ${ }^{2}$ \& \\ Sobia Hassan ${ }^{2}$ \\ 'Advocate Illinois Masonic Medical Centre, \\ USA \\ 2Rush University Medical Center, Chicago, \\ IL, USA \\ *Author for correspondence: \\ beenish_zulfiqar_ali@yahoo.com \\ (1) \\ .
}


persistent bilateral upper extremity pain and significant arm swelling with proximal muscle weakness. Her exam was notable for $4 / 5$ strength in neck flexor and extensors, 5/5 strength in bilateral deltoids, 4/5 in bilateral biceps, 4-/5 in bilateral triceps, $5 / 5$ strength in bilateral hip flexor and extensor and quadriceps. Distal extremity power was normal. Her laboratory work-up revealed CPK of 3500, $106 \mathrm{mg} / \mathrm{dl}$, AST $126 \mathrm{mg} / \mathrm{dl}$, ALT $53 \mathrm{mg} / \mathrm{dl}$, mildly elevated RF; otherwise, ANA, inflammatory markers, and complements were normal. EMG findings were suggestive of an irritative myopathy. She was evaluated by rheumatology at that time and it was felt that her presentation was more likely to represent a viral myositis than inflammatory myositis given the sudden onset of symptoms and also because of the temporal relationship to symptoms suggestive of a viral infection. She was discharged home with close follow-up. Her symptoms persisted and began to include lower extremity weakness, pain and swelling. She was again admitted to the hospital and had a muscle biopsy that showed inflammatory myopathy with myopathic changes, inflammatory infiltrates, increased labeling of endomysial capillaries for C5b-9 membrane attack complex but no perifascicular atrophy. Her CPK at this time was 2500. Given worsening symptoms, persistent hyperCKemia and biopsy results, she was started on prednisone $60 \mathrm{mg} / \mathrm{day}$. Three weeks later she returned with resolution of swelling; however, her weakness and muscle soreness persisted and she had new symptoms of dyspnea and dysphagia. Her proximal upper and lower extremity strength at this time was $3 / 5$ bilaterally. She was readmitted and started on Methylprednisone $1 \mathrm{~g} \mathrm{IV} \times 3$ days and IVIG $(2 \mathrm{~g} / \mathrm{kg}$ in divided doses over two days). Cancer screening including ovarian ultrasound, CT chest and abdomen, and mammogram were unremarkable. Paraneoplastic markers were negative. A Myomarker panel was sent and was noted to be negative for anti-SRP, anti Jo-1, EJ, OJ, Mi, Ku, MDA5, Anti HMG Co-A. She was evaluated by the neuromuscular service who reviewed her muscle biopsy and felt that her inflammatory changes were subtle and mostly identified in the perimysium region. They labeled her as having an inflammatory myopathy with perimysial pathology. Due to her severe and refractory presentation and the potential that Natalizumab might have played a role in the development of her myopathy via its immunomodulatory actions, it was discontinued.

After she completed her course of IVIG and IV methylprednisolone, her swallowing and breathing improved. She was sent to rehabilitation for strength training and recovered about $75 \%$ of her strength on follow-up. Prednisone was tapered and she was started on mycophenolate mofetil as a steroid sparing agent for her myositis.

\section{Discussion}

Adult acquired immune inflammatory myopathies are traditionally classified using the Bohan and Peter criterion which was developed in 1975 [3]. Major advances in knowledge regarding inflammatory myositis have recognized the limitations of such criteria. Developments of more recent classifications have emerged; one of which emphasized clinicoserological profiles, extra muscular organ involvement and autoantibodies [4]. These newer classifications highlight the heterogeneity of these myositis syndromes and how this has implications for prognosis and response to therapy. However, it does not take into account the pathological findings which may also have utility for distinguishing between treatable and presently untreatable AIM. For example, a patient with rapidly progressive muscle weakness with mostly necrosis and little inflammation on biopsy may perform poorly despite steroid therapy as opposed to one with inflammation but little necrosis or fibrosis. Familiarity of myopathological descriptions, then, can provide insights in to which patients would require more aggressive therapy. Myopathological classification includes description of muscle fiber pathology, immune characteristics, and types of tissues involved [2]. Currently, 6 patterns of acquired IIMs have been identified: immune myopathies with perimysial pathology (IMPP); myovasculopathies; immune polymyopathies; immune myopathies with endomysial pathology (IM-EP); histiocytic inflammatory myopathy; and inflammatory myopathies with vacuoles, aggregates and mitochondrial pathology (IMVAMP) Table 1.

Specifically, our patient had myopathy consistent with inflammatory myopathy with perimysial pathology but with negative myositis antibodies. IMPP is commonly associated with positive Anti-Jo1 antibodies. However, autoantibodies can be absent in about $20-40 \%$ of patients in patients with inflammatory myositis [57]. Patients with IMPP and positive anti-Jo-1 antibodies can have a constellation of symptoms that may include muscle weakness and pain, 


\begin{tabular}{|c|c|c|c|c|}
\hline Type & Myopathological features & $\begin{array}{l}\text { Antibodies/ } \\
\text { laboratory findings }\end{array}$ & Disease Associations & Comment(s) \\
\hline $\begin{array}{l}\text { Immune myopathies } \\
\text { with perimysial } \\
\text { pathology (IMPP) }\end{array}$ & $\begin{array}{c}\text { Fragmentation and histiocyte } \\
\text { infiltration at the perimysium. } \\
\text { Myofiber necrosis and regeneration }\end{array}$ & $\begin{array}{c}\text { anti-tRNA synthetase } \\
\text { antibodies,(Jo-1, PL-7, } \\
\text { PL-12) }\end{array}$ & $\begin{array}{c}\text { Dermatomyositis, } \\
\text { polymyositis, interstitial } \\
\text { lung disease, fasciitis, graft } \\
\text { vs. host disease, some toxic } \\
\text { myopathies }\end{array}$ & $\begin{array}{c}\text { Common } \\
\text { pattern, Aldolase } \\
\text { selectively high, } \\
\text { Not in hereditary } \\
\text { myopathies }\end{array}$ \\
\hline Myovasculopathies & $\begin{array}{c}\text { Perifascicular atrophy and } \\
\text { vacuolation with little necrosis or } \\
\text { focal invasion by mononuclear cells }\end{array}$ & & $\begin{array}{l}\text { Dermatomyositis in childhood } \\
\text { and some adults May be } \\
\text { associated with calcinosis } \\
\text { Paraneoplastic syndromes }\end{array}$ & \\
\hline $\begin{array}{l}\text { Immune } \\
\text { polymyopathies }\end{array}$ & $\begin{array}{l}\text { Myofibers may have varying stages } \\
\text { of necrosis and regeneration } \\
\text { (early stages) or less necrosis and } \\
\text { regeneration (later stages) No } \\
\text { mononuclear cell infiltration }\end{array}$ & $\begin{array}{l}\text { SRP and HMG-CoA } \\
\text { reductase (HMG-CoAR) } \\
\text { antibodies }\end{array}$ & $\begin{array}{c}\text { Statin use (HMG-CoAR } \\
\text { antibodies) Paraneoplastic } \\
\text { syndromes }\end{array}$ & $\begin{array}{l}\text { CK is very high, } \\
\text { Differs from } \\
\text { rhabdomyolysis } \\
\text { in which many } \\
\text { damaged fibers have } \\
\text { a similar stage of } \\
\text { pathology }\end{array}$ \\
\hline $\begin{array}{l}\text { Immune and } \\
\text { inflammatory } \\
\text { myopathies } \\
\text { with endomysial } \\
\text { Pathology (IIM-EP) }\end{array}$ & $\begin{array}{l}\text { Endomysial molecular pathology } \\
\text { that often requires special stains for } \\
\text { demonstration. }\end{array}$ & & $\begin{array}{c}\text { Brachio-cervical inflammatory } \\
\text { myopathy (BCIM) }\end{array}$ & \\
\hline $\begin{array}{l}\text { Histiocytic } \\
\text { inflammatory } \\
\text { myopathies }\end{array}$ & $\begin{array}{l}\text { Histiocytic foci in the endomysium } \\
\text { or perimysium. Myofibers are } \\
\text { replaced by histiocytic cells and } \\
\text { endomysial connective tissue. }\end{array}$ & & $\begin{array}{l}\text { Granulomatous myopathies, } \\
\text { i.e. sarcoidosis Macrophagic } \\
\text { myofasciitis (MMF) } \\
\text { Inflammatory myopathy } \\
\text { with abundant macrophages } \\
\text { (IMAMs) }\end{array}$ & $\begin{array}{l}\text { Both MMF and } \\
\text { IMAMs can be related } \\
\text { to immunizations } \\
\text { and may be clinically } \\
\text { silent }\end{array}$ \\
\hline $\begin{array}{l}\text { Inflammatory } \\
\text { myopathies with } \\
\text { vacuoles, aggregates } \\
\text { and mitochondrial } \\
\text { pathology (IM-VAMP) }\end{array}$ & $\begin{array}{l}\text { Multifocal mononuclear cell } \\
\text { inflammatory foci, mostly CD4+ and } \\
\text { CD8+ T cells, in the endomysium } \\
\text { in a linear or sinuous pattern. } \\
\text { Perivascular foci may also occur. } \\
\text { Myofibers may contain vacuoles, } \\
\text { aggregates and mislocalized } \\
\text { proteins or mitochondrial } \\
\text { pathology. }\end{array}$ & & Inclusion body myositis (IBM) & $\begin{array}{c}\text { Disease progression } \\
\text { may be more rapid } \\
\text { in IM-VAMP with } \\
\text { vacuoles than those } \\
\text { with mitochondrial } \\
\text { pathology and no } \\
\text { vacuoles }\end{array}$ \\
\hline
\end{tabular}

Raynaud's phenomenon, interstitial lung disease, arthritis, and a skin rash, commonly known as antisynthetase syndrome, different from that seen in classic dermatomyositis. In a case series, review of charts, muscle biopsies and laboratory records by Mozaffar $\mathrm{T}$ et al. [8], features of myopathology in 11 patients with anti-Jo-1 antibody associated myopathies were compared with other types of inflammatory myopathies. Electromyography in nine patients tested showed an irritable myopathy. Muscle biopsies from all 11 patients with antiJo-1 antibodies contained regions of fragmented, rarefied perimysial connective tissue. Inflammation was less common in endomysial (two of $11 ; 18 \%$; $\mathrm{p}=0.003$ ) and perivascular (one of $11 ; 9 \%$; $\mathrm{p}<0.001)$ regions of muscles. In another report high serum aldolase, normal creatine kinase, and systemic features common to antisynthetase syndromes were associated with IMPP [8]. Among the biopsies that were reviewed in this report, 5 were with negative anti-Jo1 antibodies.
IMPP syndromes are generally responsive to immunomodulatory therapy, including corticosteroids and other drugs [9]. Our patient had symmetric proximal muscle weakness but also had significant bilateral arm swelling. She did not have lung involvement during her course. She was initially resistant to high dose steroids but on cessation of her natalizumab therapy and with the addition of IVIG and a prolonged course of oral steroids after pulsed treatment with IV methylprednisolone, she eventually started to show improvement. By 9 months follow-up, her motor strength was $5 / 5$ on bilateral proximal upper extremities, $4 / 5$ on both hip flexors, and 5/5 bilateral hip extensors and thigh adductors and abductors. Our patient had received Natalizumab for treatment of relapsing MS 1 year prior to the onset of her myositis. Although no prior case reports were found in our literature review, based on its mechanism of action, it was hypothesized that natalizumab caused immune dysregulation that may have 
contributed to the development and severity of our patient's myopathy. Natalizumab works by targeting cellular adhesion and $\mathrm{T}$ cell migration $[10,11]$. It acts against the a4b1 integrin, VLA4, on leucocytes, which are fundamental molecules for adhesion and transmigration of $\mathrm{T}$ cells. It has been used in Crohn's disease and multiple sclerosis. In the myositis group of diseases, it has actually been studied as a treatment for inclusion body myositis. The final results of this study are not available yet but interim analysis of a pilot trial showed significant changes in muscle biopsies of 2 patients with near complete elimination of inflammation [10]. No changes in the manual muscle testing were noted in these two patients. Treatment of rare diseases or rare disease manifestations in rheumatology are often mirrored on previous experiences of similar more common disease presentations. In a review of natalizumab, it was suggested that it could be a potential therapy for refractory cases or difficult cases of polymyositis, dermatomyositis and IBM. Limited literature is available in support of this, however given the temporal relationship between starting natalizumab and the onset of our patient's symptoms, it is postulated that natalizumab may have played a role in the onset or severity of her myositis. It is speculated that natalizumab, given its mechanism of action, may affect the normal trafficking of lymphocytes and may have perturbed the balance between effector and regulatory $\mathrm{T}$ cells. Discontinuation of the drug and aggressive therapy for her myositis led to a gradual improvement in her symptoms. Even though the link between our patient's myositis and natalizumab use is only hypothetical, the fact that natalizumab is being considered as a treatment for refractory or resistant cases of inflammatory myositis should raise some concern and needs further investigation.

\section{Conclusion}

In summary, we report an atypical presentation of adult inflammatory myopathy with perimysial pathology in the setting of known MS and natalizumab use. We did not find any other case reports implicating natalizumab in the onset of inflammatory myopathy. To the contrary, it has been suggested as a potential treatment for refractory inflammatory myopathy in a few studies. However, the temporal relationship between the development of inflammatory myopathy in our patient and subsequent improvement in her course after discontinuation of the drug suggests that natalizumab may have played a role in our patient's disease and warrants further investigation and vigilance.

This report also provides a review of the myopathological classifications of inflammatory myopathies which are increasingly being used and can potentially provide additional information about prognostication and response to therapy.

\section{References}

1. Pestronk A. Acquired immune and inflammatory myopathies: pathologic classification. Curr. Opin. Rheumatol. 23, 595-604 (2011).

2. Nozaki KPA. High aldolase with normal creatine kinase in serum predicts a myopathy with perimysial pathology. J. Neurol. Neurosurg. Psychiatry. 80, 904 908 (2009).

3. Bohan A, Peter JB. Polymyositis and dermatomyositis (first of two parts). N. Engl. J. Med. 292(7), 344-7 (1975).

4. Senécal JL, Raynauld JP, Troyanov Y. Editorial: A New Classification of Adult Autoimmune Myositis. Arthritis \& Rheumatology. 69(5), 878-884 (2017).

5. Dakkalas MC. Inflammatory muscle diseases. N. Engl. J. Med. 372(18), 1734-47 (2015).

6. Koenig M, Fritzler JM, Targoff IN et al. Heterogeneity of autoantibodies in 100 patients with autoimmune myositis: insights into clinical features and outcomes. Arthritis Research \& Therapy. 9(4), 78 (2007).

7. Aggarwal R, Bandos A, Reed AM et al. Predictors of Clinical Improvement in Rituximab-Treated Refractory Adult and Juvenile Dermatomyositis and Adult Polymyositis. Arthritis. Rheumatol. 66(3), 740-9 (2014).

8. Mozaffar T, Pestronk A. Myopathy with anti-Jo-1 antibodies: pathology in perimysium and neighbouring muscle fibres. J. Neurol. Neurosurg. Psychiatry. 68(4), 472-8 (2000).

9. Nozaki K, Pestronk A. High Aldolase with Normal Creatine Kinase in serum predicts a Myopathy with Perimysial Pathology. J. Neurol. Psychiatr. Neurosurg. 80, 829-829 (2009).

10. Kleinschmidt-DeMasters BK, Tyler KL. "Progressive multifocal leukoencephalopathy complicating treatment with natalizumab and interferon beta-1a for multiple sclerosis". N. Engl. J. Med. 353(4), 369-74 (2005).

11. Zohren F, Toutzaris D, Klarner V et al. "The monoclonal anti-VLA4 antibody natalizumab mobilizes CD34+ hematopoietic progenitor cells in humans". Blood. 111(7), 3893-5 (2008).

12. Gunawardena H, Wedderburn LR. Autoantibodies to a $140-\mathrm{kd}$ protein in juvenile dermatomyositis are associated with calcinosis. Arthritis. Rheum. 60(6), 1807-14 (2009).

13. Bleecker JLD, Lundberg IE. Pathology diagnosis of idiopathic inflammatory myopathies 30 November - 2 December 2012, Naarden, The Netherlands. Neuromuscular Disorders. 23, 945-951 (2013). 
14. Stenzel W, Goebel HH, E Aronica. Immune-mediated necrotizing myopathies - a heterogeneous group of diseases with specific myopathological features. Neuropathol. Appl. Neurobiol. 38, 632-646 (2012).
15. Lazarou IN, Guerne PA. Classification, Diagnosis, and Management of Idiopathic Inflammatory Myopathies. J. Rheumatol. 40 (2013). 